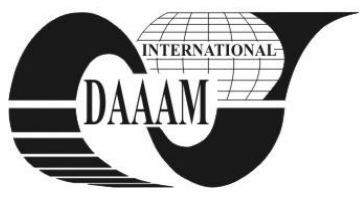

Annals of DAAAM for 2011 \& Proceedings of the 22nd International DAAAM Symposium, Volume 22, No. 1, ISSN 1726-9679 ISBN 978-3-901509-83-4, Editor B. Katalinic, Published by DAAAM International, Vienna, Austria, EU, 2011 Make Harmony between Technology and Nature, and Your Mind will Fly Free as a Bird Annals \& Proceedings of DAAAM International 2011

\title{
A HOLISTIC APPROACH FOR ENERGY EFFICIENT PRODUCTION FACILITIES
}

\author{
DIMITRIOU, A[lexandros] A[thanassios]; DORN, C[hristoph] \& BLEICHER, F[riedrich]
}

\begin{abstract}
Over the past years sustainability has gained importance throughout Europe. Uncertainty over the future development of energy prices, tighter EU regulations and increasing ecological awareness among the public push for changes in the way resources are managed by manufacturing companies. The Vienna University of Technology has initiated its own showcase project in this promising field with project INFO (Interdisciplinary Research for Energy Efficiency in Production), funded by the Austrian Research Promotion Agency. The main aim of this project is an integrated simulation instrument for optimizing entire production facilities energetically, that considers all interactions within such a system. The following paper will briefly introduce the methodology of integrating these components, from the micro level of the machine tool to the macro level of the building envelope. By modeling the facility, the manufacturing system and the production machines as a whole, energy efficiency measures can be identified, evaluated and optimized. The simulation concept is flexible, in order to allow application to a wide variety of industrial facilities and illustrate the opportunities each facility presents individually. As an example, a specific production facility focusing on metalworking was analyzed and modeled using this method. Assuming a base scenario for each component allowed us to implement the interacting variables. Subsequent variation of these inputs enabled the optimization of chosen factors.

Key words: sustainable manufacturing, integrated simulation, energy optimized production facilities
\end{abstract}

\section{INTRODUCTION}

The simulation concept behind the integration of all components of a production facility in one integrated simulation instrument consists of the analysis and modeling of these systems and the combination of the dynamic interactions that occur between them.

The components of a production facility were identified as:

- The machining process

- The machine tool

- The production system

- The building

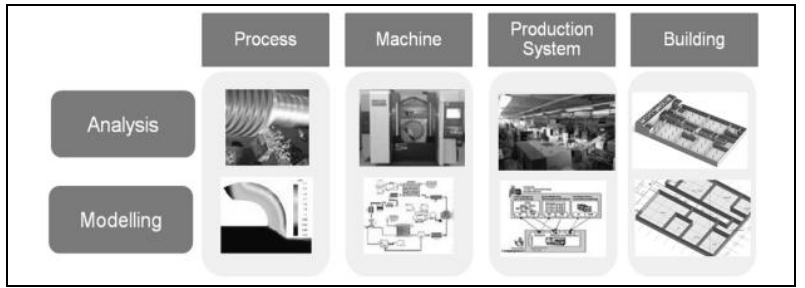

Fig. 1. Integration concept [Dorn, Kovacic, Orehounig]

The simulation concept allowed all influencing variables to be implemented in the system, taking into consideration the production system and fluctuations of the output, the energetic characteristics of the machinery for processing various parts and the physical properties of the building envelope, Fig. 1. Emitted heat from the machines was quantified by measurements under different production modes, resulting scenarios from this data acted as an input for the simulation of the building using E-plus simulation software, with the building type having previously been defined according to architectural and functional criteria.

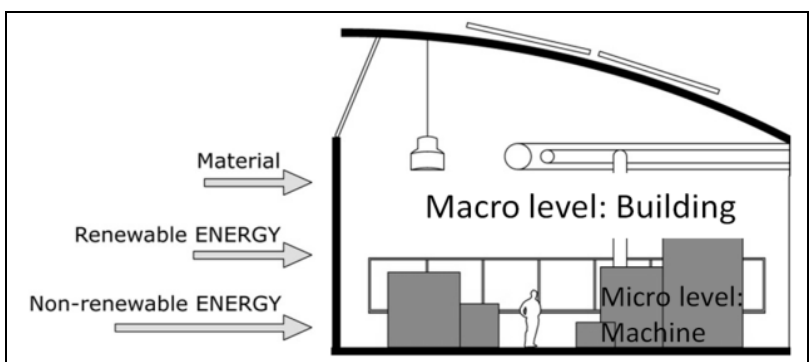

Fig. 2. Integration of components

\section{ENERGETIC CHARACTERISTICS OF THE MACHINERY}

\subsection{Background}

The main interaction between the factory building and the production machines within is the heat that is emitted from the machinery during processes such as milling, turning and laser cutting. As studies by the Institute for Production Engineering and Laser technology (IFT) of the Vienna UT have confirmed, machine tools for metalworking e.g. milling and turning machines act as considerable heat sources in a production facility. The fraction of the machining energy going into a chip that is not transformed into heat can be assumed to vary between 3 and 30\%. This fraction consists of the plastic work associated with the chip removal process Fig. 3 [Tönshoff], [Müller].

The energy that is required in chip formation is far from the total energy required in production. For these processes additional energy must be provided to power auxiliary equipment for workpiece handling, cutting fluid handling, chip handling, tool changers, computers, cooling equipment and machine lubrication systems [Gutowski].

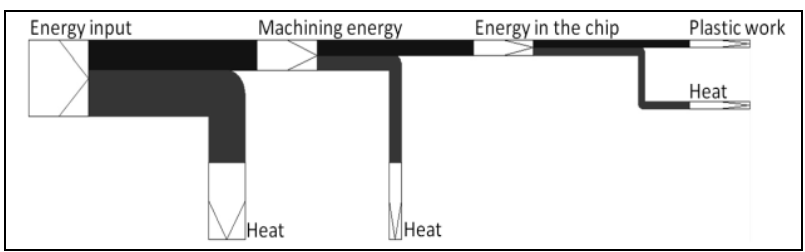

Fig. 3. Energy flow in a machining process

Further, by considering the machining time in metalworking the fraction of the plastic work is reduced further [Dahmus]. In general it can be assumed that all of the electrical 
energy that is inserted into the factory will be emitted inside the factory in the form of heat.

\subsection{Machining scenarios}

Emitted heat from the machinery is the main interaction with the building. To integrate this dynamic interaction into the model, a method of recomposing individual measurements to production scenarios that describe the emitted heat has been developed at the IFT. To reproduce these scenarios from measurements, the following data is of importance:

- machining intensity

- machine usage

- number of shifts

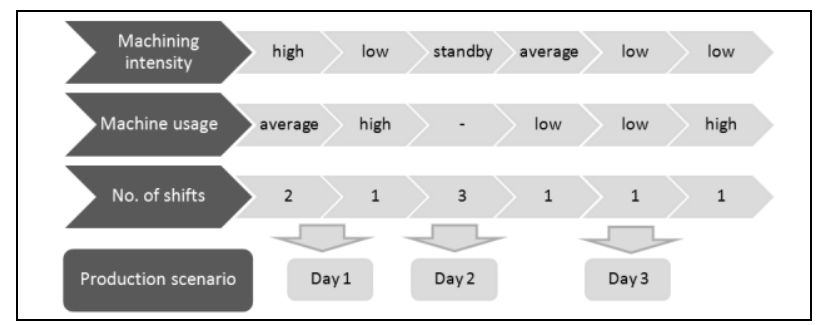

Fig. 4. Machining scenario components

The recomposed scenarios allow us to model the energy consumption of the machinery under current circumstances and also to forecast future consumption. Moreover this method can illustrate the impact of an intervention in the production system in terms of energy demand, e.g. quantifying how much energy can be saved when the machines are shut down completely instead of being run on standby when they are not being used.

\section{BUILDING CONCEPT}

The general architectural building concept was introduced and acted as an input constant. During this phase the main goals of the design were identified as:

- Improved communication

Between R\&D and production hall

- Flexibility

Adaptability for different area functions

- Expandability

With minimal re-fitting effort

- Energy efficiency

Minimized energy consumption for HVAC/Lighting

The resulting building design, after consideration of these goals, consisted of a functional layout, with office blocks facing north, to minimize overheating, and a production hall with storage, delivery and R\&D as a single unit. Functionality was enhanced by a modular grid design with $15 \times 15 \mathrm{~m}$ elements for flexibility and expandability.

Communication between the $R \& D$ and production divisions was upgraded by arranging the offices in a "spine" design directly above the production hall using glass elements, as depicted in Fig. 5.

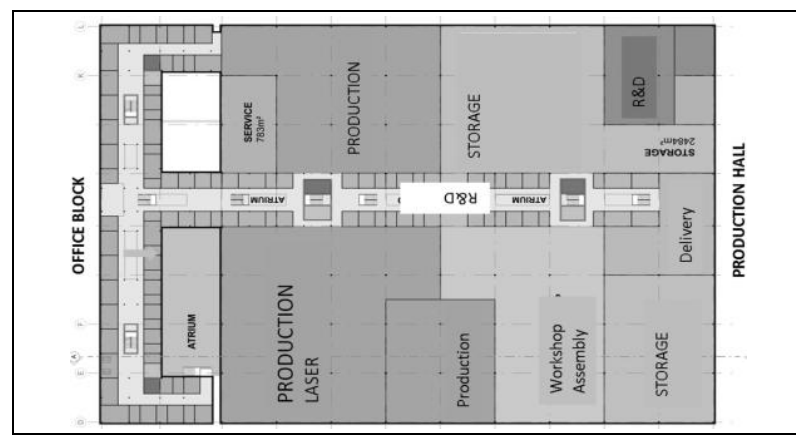

Fig. 5. Facility layout [Dorn, Kovacic, Orehounig]

\section{BUILDING PERFORMANCE}

The building was simulated in the design process, using the E-plus simulation software. Variable input parameters at this stage allowed for evaluation of different building properties regarding their performance on criteria such as the visual and thermal comfort (overheating, glare, etc.) that they provided and the energy requirements (HVAC, lighting) they induced.

Following input parameters were included in the simulation:

- Geometry and building elements

U-Values

- Internal gains-heat sources

Workers, machining scenarios

- Weather data

Hourly statistical data for the specific geographic position

- Systems

HVAC/Lighting

Using our integrated simulation, the building performance model allowed us to change parameters such as air change rates, digitally enable automated lighting control or automated Shading and evaluate the impact of these measures on our facility's energetic performance. Different possibilities arose for either reducing the cooling load in the summer, the heating load in the winter or choosing the economically best option, keeping in mind that cooling is more expensive than heating.

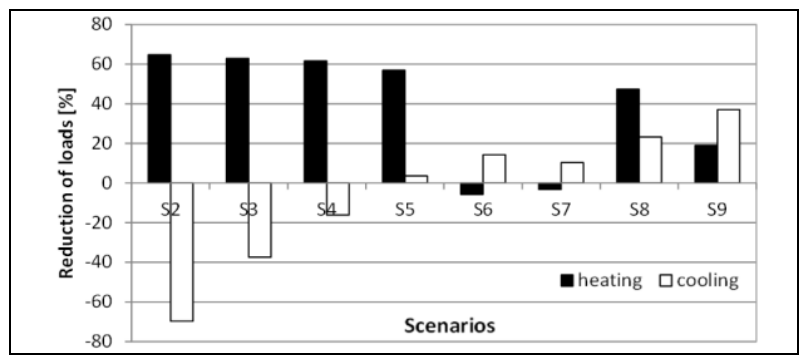

Fig. 6. Load reductions with implementation of different measures [Dorn, Kovacic, Orehounig]

\section{CONCLUSION}

An integrated simulation that includes all interactions in a production facility has been developed at the Vienna UT. The dynamic interactions were simplified and composed into a model that allows the improvement of each component individually and altogether as the overall system.

Depending on the selection criterion of what we want to optimize, using this integrated simulation tool can help implement specific solutions on the facility leading to quantified results, e.g. to assess if installing waste heat recovery systems to the machinery is ecologically worthwhile, taking into account interactions this installation creates with the building services. First results are promising that this tool will contribute to bringing more sustainability into manufacturing, by simultaneously cutting emissions and energy costs.

\section{REFERENCES}

Tönshoff, H.K. (2003). Spanen, Springer Verlag, ISBN 3-540-00588-9, Berlin Heidelberg

Müller, B. (2004). Thermische Analyse des Zerspanens metallischer Werkstoffe bei hohen Schnittgeschwindigkeiten Dissertation - RWTH Aachen, Aachen

Gutowski, T.G. (2006). Electrical Energy Requirements for Manufacturing Processes, 13. CIRP, Leuven.

Dahmus, J. (2004) An environmental analysis of machining, IMECE 2004, Anaheim

Dorn, Kovacic, Orehounig, (2011). Energy Efficient Production - Interdisciplinary, Systemic Approach through Integrated Simulation, 6. Conference on Sustainable Development of Energy, Water and Environment Systems, Dubrovnik 